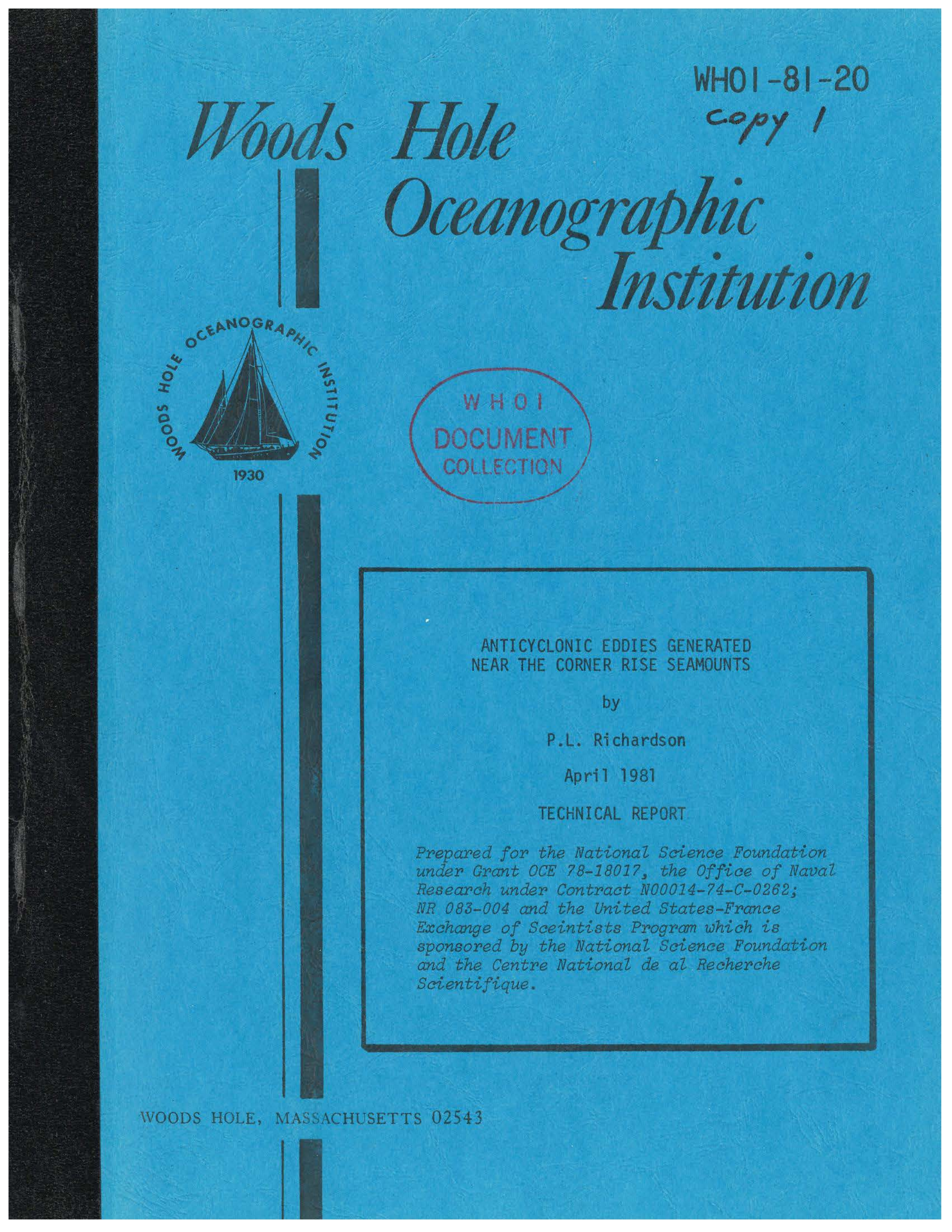


WHOI $-81-20$

ANTICYCLONIC EDDIES GENERATED

NEAR THE CORNER RISE SEAMOUNTS

by

P.L. Richardson

WOODS HOLE OCEANOGRAPHIC INSTITUTION

Woods Hole, Massachusetts 02543

Apri1 1981

TECHNICAL REPORT

Prepared for the National Science Foundation under Grant OCE 78-18017, the Office of Naval Research under Contract N00014-74-C-0262; NR 083-004 and the United States-France Exchange of Scientists Program sponsored by the National Science Foundation and the Centre National de al Recherche scientifique.

Reproduction in whole or in part is permitted for any purpose of the United States Govemment. In citing this report in a bibliography, the reference given should be to: Jourmal of Marine Research 38 (4): 673-686. (July 1980).

Approved for public release; distribution unlimited.

Approved for Distribution: Valentine Worthington, Chairman Department of Physical Oceanograpy 


\title{
Anticyclonic eddies generated near the Corner Rise seamounts
}

\author{
by P. L. Richardson ${ }^{1}$
}

\begin{abstract}
During 1977 two freely drifting buoys, originally in the Gulf Stream, looped over and in the lee of the Corner Rise seamounts. The trajectories suggest that by mid-August an anticyclonic eddy was generated over the seamounts, where it remained for six weeks. During the period October-December it left the seamounts and drifted southwestward with a mean speed of $5 \mathrm{~cm} / \mathrm{sec}$. The eddy was characterized by a clockwise circulation with speeds of $30 \mathrm{~cm} / \mathrm{sec}$ and an overall size of $200 \mathrm{~km}$. An XBT survey showed that the eddy contained a warm core manifested by a depression of the main thermocline; at the center the $15^{\circ}$ isotherm was located at a depth of $715 \mathrm{~m}$. During the period June-August a third buoy looped in a second anticyclonic eddy which also drifted southwestward in the lee of the Corner Rise. The implication of these measurements is that, every few months, warm core eddies form near the Corner Rise and that they subsequently drift southwestward forming a wake region downstream of the seamounts.
\end{abstract}

\section{Introduction}

Recently, free-drifting buoys in the Gulf Stream system have shown that surface currents are frequently strongly influenced by individual seamounts as well as by clusters of seamounts. The surprising result is that mesoscale eddies are formed over and in the lee of seamounts and that these eddies extend all the way to the surface where they are detected by buoys as regions of closed loops. The results imply that seamounts can be an important source region for mesoscale motion and that they may significantly affect the general circulation.

Buoy trajectories indicate the presence of topographic eddies in many areas including the New England seamounts in the Atlantic and the Emperor seamounts in the Pacific; however, one of the clearest examples comes from the Corner Rise seamounts located south of Newfoundland and east of North Carolina. Buoy and XBT observations made in 1977 near these seamounts give the best evidence to date on the existence and character of an eddy generated by seamounts.

\section{The buoys}

The buoys were made by Polar Research Laboratory, had a usual life of 9-12

1. Woods Hole Oceanographic Institution, Woods Hole, MA 02543 


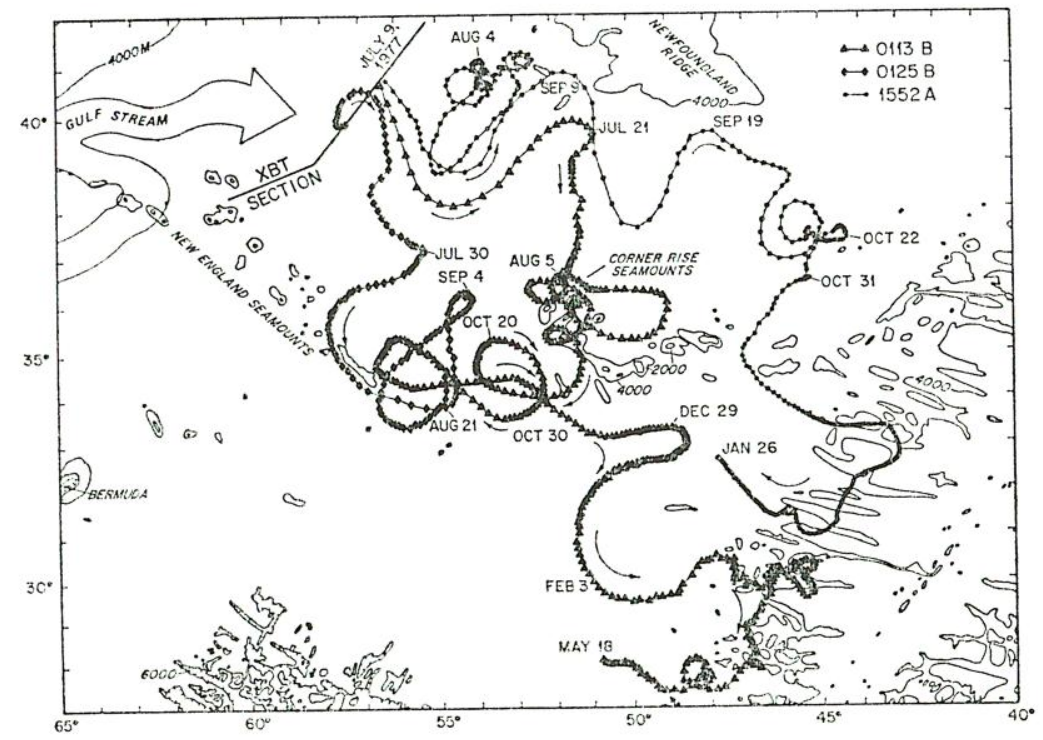

Figure 1. Trajectories of three free-drifting buoys launched across the width of the Gulf Stream near 57W on July 9, 1977. One of the buoys, 0113B, launched near the center of the Stream, moved southward with a mean speed of $30 \mathrm{~cm} / \mathrm{sec}$ between 37 and $39 \mathrm{~N}$ and looped over and southwestward of the Corner Rise seamounts. The trajectory of buoy 0154B is not shown because it was short and closely followed the path of buoy 0125B. Two positions per day are shown for each buoy.

months and carried a temperature and drogue sensor. Positions were determined by NASA from the Doppler shifted radio signal received by the Nimbus F satellite. Typically two good fixes per day were obtained for each buoy; the rms error of the fixes was estimated to be one to two kilometers. Trajectories and velocity along trajectories were computed and plotted by fitting a cubic spline function through the measured positions and by interpolating two positions, velocity, and temperature values per day evenly spaced in time. A more complete description of the buoys and data is given by Richardson, Wheat, and Bennett (1979).

Although virtually all the buoys had a $25 \mathrm{~m}^{2}$ window shade drogue and a $200 \mathrm{~m}$ tether of $3 \mathrm{~cm}$ diameter polypropylene attached to them when they were launched, the period of time that the drogues remained attached is unknown (except for buoy 1076A, whose drogue came off thirteen days after launch.) This is because the drogue sensors failed due to overloading after a few weeks at sea. It seems probable, based on the buoys we retrieved, that the drogues usually remained attached to the buoys for a few months. Because of the uncertainty of the presence or not of the drogues, there is the uncertainty whether the buoys were measuring the currents in the upper $2 \mathrm{~m}$, the depth of the hull, or in the upper $200 \mathrm{~m}$. It is probably more correct to assume the former. 


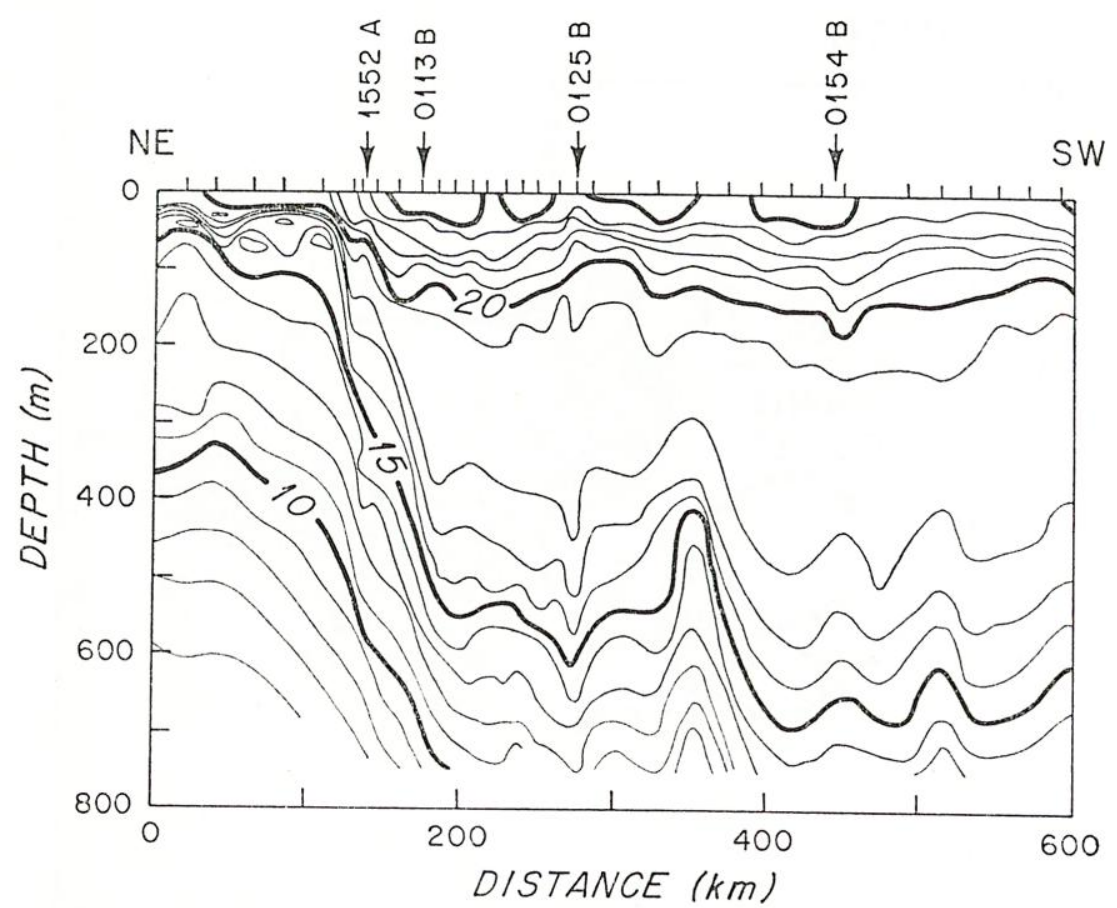

Figure 2. XBT section from KNORR 66 across the Gulf Stream near 57W on July 9, 1977 and locations at which the buoys were launched.

The motion of the buoys directly induced by the local wind appears to be small at least in high velocity regions of the ocean such as the Gulf Stream system. Evidence for this conclusion comes from numerous buoys that were located in Gulf Stream rings for long periods of time, up to eight months, despite high winds.

\section{Corner Rise seamounts}

The Corner Rise consists of a $150 \mathrm{~km}$ diameter, circular cluster of six individual seamounts rising from the depth of the sea floor at $5200 \mathrm{~m}$ up to $650 \mathrm{~m}$ (Uchupi, 1971; McGregor, Betzer, and Krause, 1973). From this main cluster a tail of seamounts curves southward and eastward extending a distance of $300 \mathrm{~km}$. Individual peaks along the tail reach to within $940 \mathrm{~m}$ of the ocean surface, 82 percent of the nearby water depth.

The central cluster of seamounts is located near $36 \mathrm{~N} 52 \mathrm{~W}$, an area in which the Gulf Stream recirculation flows southwestward. The mean southwestward current is seen on Worthington's (1976) chart of the North Atlantic currents as well as on charts of ship drift measurements (Naval Oceanographic Office, 1978), charts of dynamic topography (Stommel, Niiler, and Anati, 1978), and in the results of POLYMODE current meter array II from 55W (Schmitz, 1979). 
$0113 \mathrm{~B}$

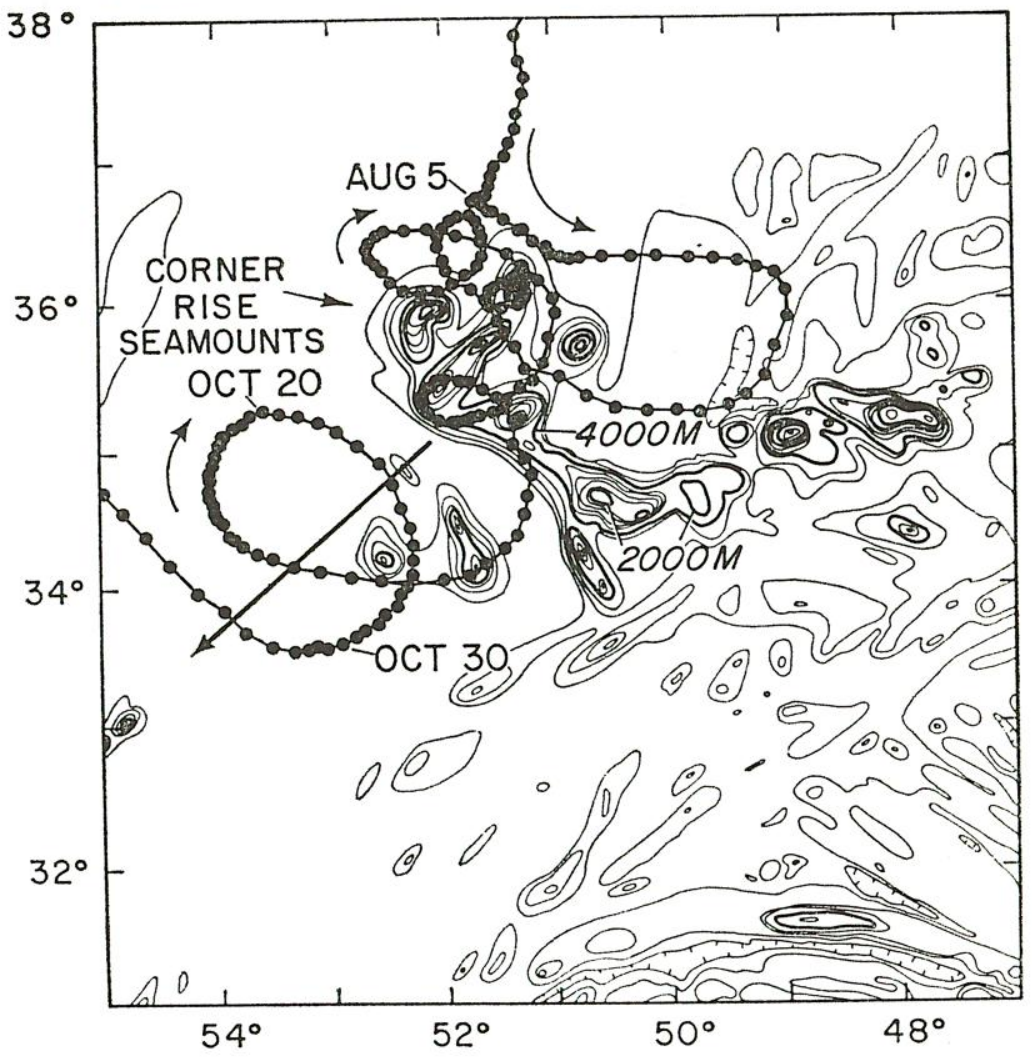

Figure 3. Trajectory of buoy $0113 \mathrm{~B}$ as it looped over the Corner Rise seamounts from August 5 to November 5, 1977. The main cluster of seamounts is located near $36 \mathrm{~N} 52 \mathrm{~W}$ and consists of six individual peaks rising from a depth of $5200 \mathrm{~m}$ up to $650 \mathrm{~m}$ (Uchupi, 1971).

\section{Buoy trajectories}

In July 1977 four buoys, 0113B, 0125B, 0154B, and 1552A were launched in the Gulf Stream along 57W (Figs. 1 and 2). One of these, 0113B, originally located near the center of the Stream, moved eastward, then southward and looped over and in the lee of the Corner Rise seamounts. As buoy 0113B approached the seamounts in early August 1977 with a mean speed of $30 \mathrm{~cm} / \mathrm{sec}$ (averaged between 37 and $39 \mathrm{~N}$ ), it slowed and stopped as if reaching a stagnation point in front of the seamounts (Fig. 3). Buoy 0113B then became entrained into an anticyclonic eddy located over the cluster of seamounts and, during the next six weeks, made four clockwise loops in the eddy. The average period of the loops was 12 days, the mean swirl speed was $26 \mathrm{~cm} / \mathrm{sec}$ and the diameter increased from 40 to $100 \mathrm{~km}$ (Figs. 4 and 5). During these first four loops the eddy looked as if it was trapped 

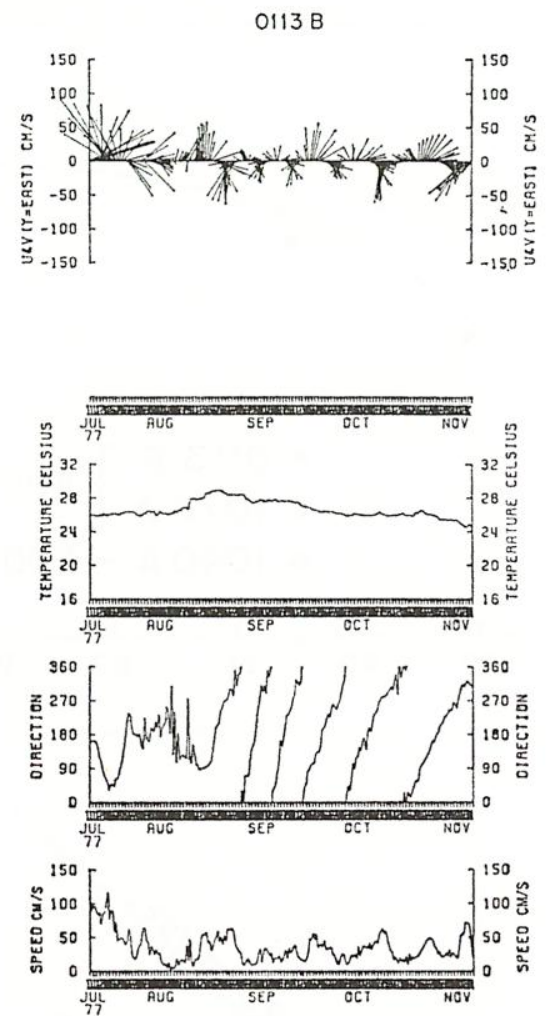

Figure 4. Time series of velocity, temperature, direction and speed along the trajectory of buoy 0113B from July 9 to November 5, 1977. The speed decreased from $100 \mathrm{~cm} / \mathrm{sec}$ to zero as the buoy approached the seamounts. The looping motion is clearly seen in the direction series; the period of rotation increased from 8 days at the beginning to 23 days at the end, perhaps indicating the decay of the eddy. The time-variation in rotation rate can also be explained by a radial movement of the buoy in the presence of radial shear in the swirl velocity.

over the seamounts suggesting the presence of a Taylor column. The buoy looped once more as the eddy (Eddy I) in which it was moving drifted away to the southwest presumably in the large-scale flow in which the eddy was embedded.

Additional evidence of the persistence and movement of Eddy I is given by the trajectory of buoy 1076A which was also in the Gulf Stream and approached the seamounts from the north. Buoy 1076A was entrained into the clockwise circulation of the eddy just as it moved away from the seamounts (Fig. 6). In September, 1977 as buoy 0113B was looping over the top of the seamount cluster, buoy 1076A approached the seamounts with a mean speed of $50 \mathrm{~cm} / \mathrm{sec}$ and appeared to be deflected around the eastern side of the cluster and eddy. Eddy I moved away from the seamounts, buoy 1076A was entrained into its circulation and made three 

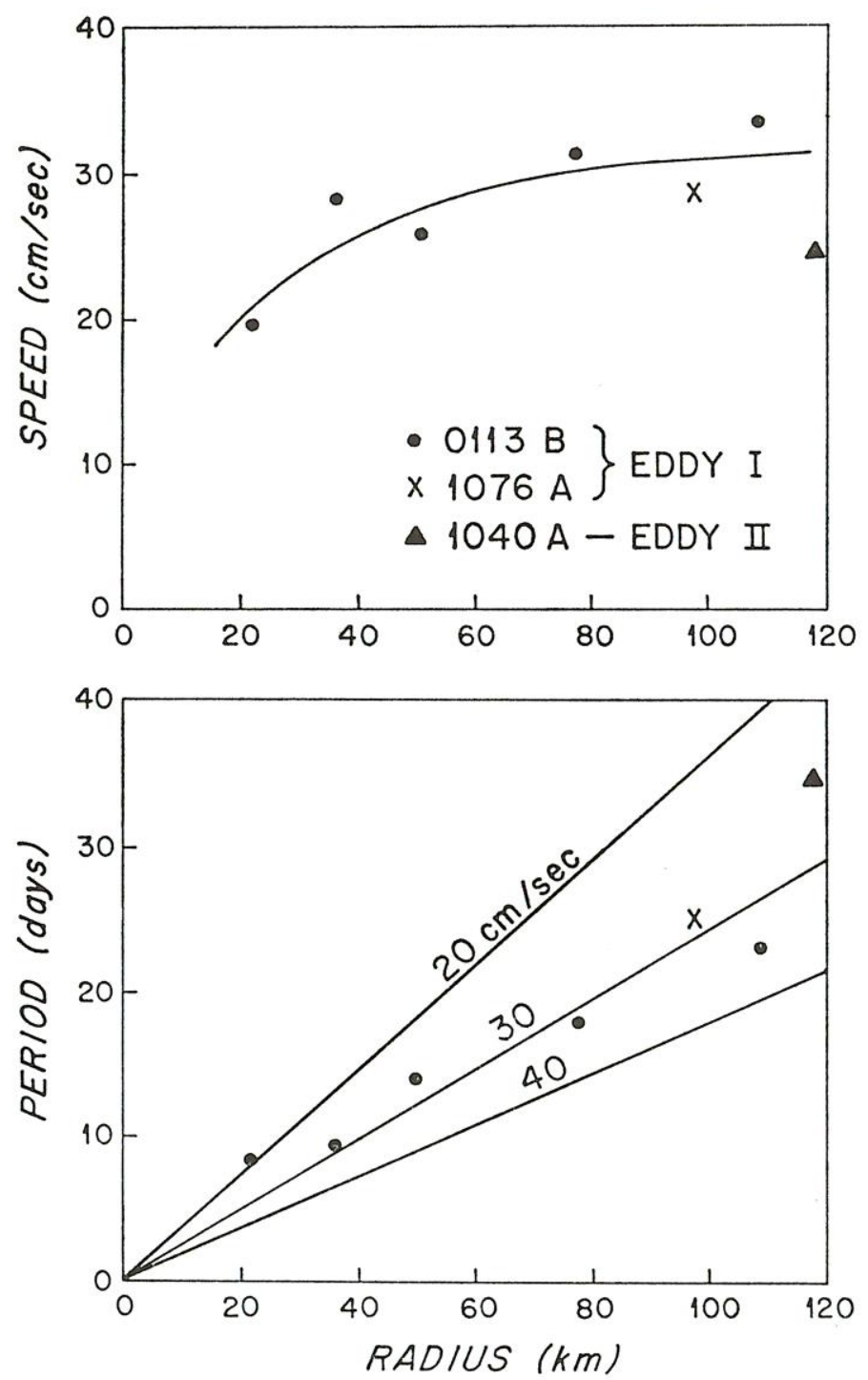

Figure 5. Speed and period of rotation in Eddy I (0113B and 1076A) and Eddy II (1040A). Values of buoy 0113B are estimations from individual loops that were increasing in radius and period of rotation. Swirl speeds in Eddy I were typically $30 \mathrm{~cm} / \mathrm{sec}$.

clockwise loops which had a characteristic period of rotation of 25 days, swirl speed of $28 \mathrm{~cm} / \mathrm{sec}$ and diameter of $200 \mathrm{~km}$. The two buoys, 0113B and 1076A, suggest that Eddy I had formed over the seamounts before August 5, 1977, when buoy $0113 \mathrm{~B}$ stopped in front of the seamounts implying the presence of the eddy, that it began to move away from the seamounts on October 1 and that it con- 


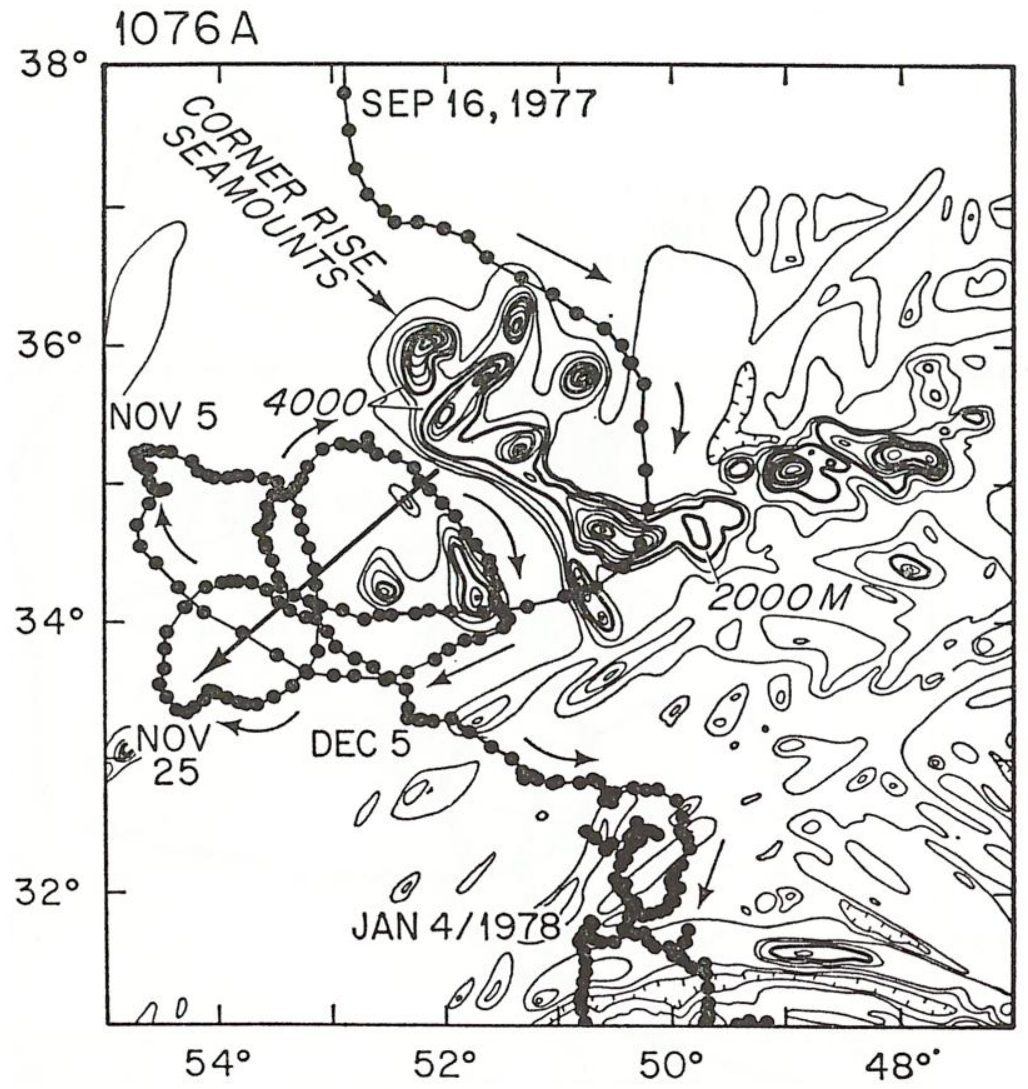

Figure 6. Trajectory of buoy 1076A which was entrained into Eddy I and looped three times as it drifted southwestward away from the seamounts with a mean speed of $5 \mathrm{~cm} / \mathrm{sec}$.

tinued to move southwestward with a mean speed of $5 \mathrm{~cm} / \mathrm{sec}$ until December 5 , 1977 when the last buoy, 1076A, came out of it and stopped looping. The life of the eddy was therefore at least four months.

A third buoy provided evidence of a second eddy (Eddy II) in the lee of the Corner Rise (Fig. 7). During May 1977, buoy 1040A drifted southward toward the Corner Rise in a branch of the Gulf Stream (Fig. 8) and with a mean speed of $135 \mathrm{~cm} / \mathrm{sec}$. This buoy passed around the eastern side of the seamounts and made two large, clockwise loops southwestward of them. The mean period of rotation of the loops was 35 days, the mean diameter was $240 \mathrm{~km}$ and the mean swirl speed was $24 \mathrm{~cm} / \mathrm{sec}$ (Fig. 5). The movement of Eddy II was towards the southwest with a speed, estimated from the two loops, of $4 \mathrm{~cm} / \mathrm{sec}$.

The shape of the three trajectories, the size and location of the loops in the two eddies, suggests that the dominant influence on the flow was the integrated effect of the seamounts as opposed to a single seamount. Both the size of the loops of 
$1040 \mathrm{~A}$

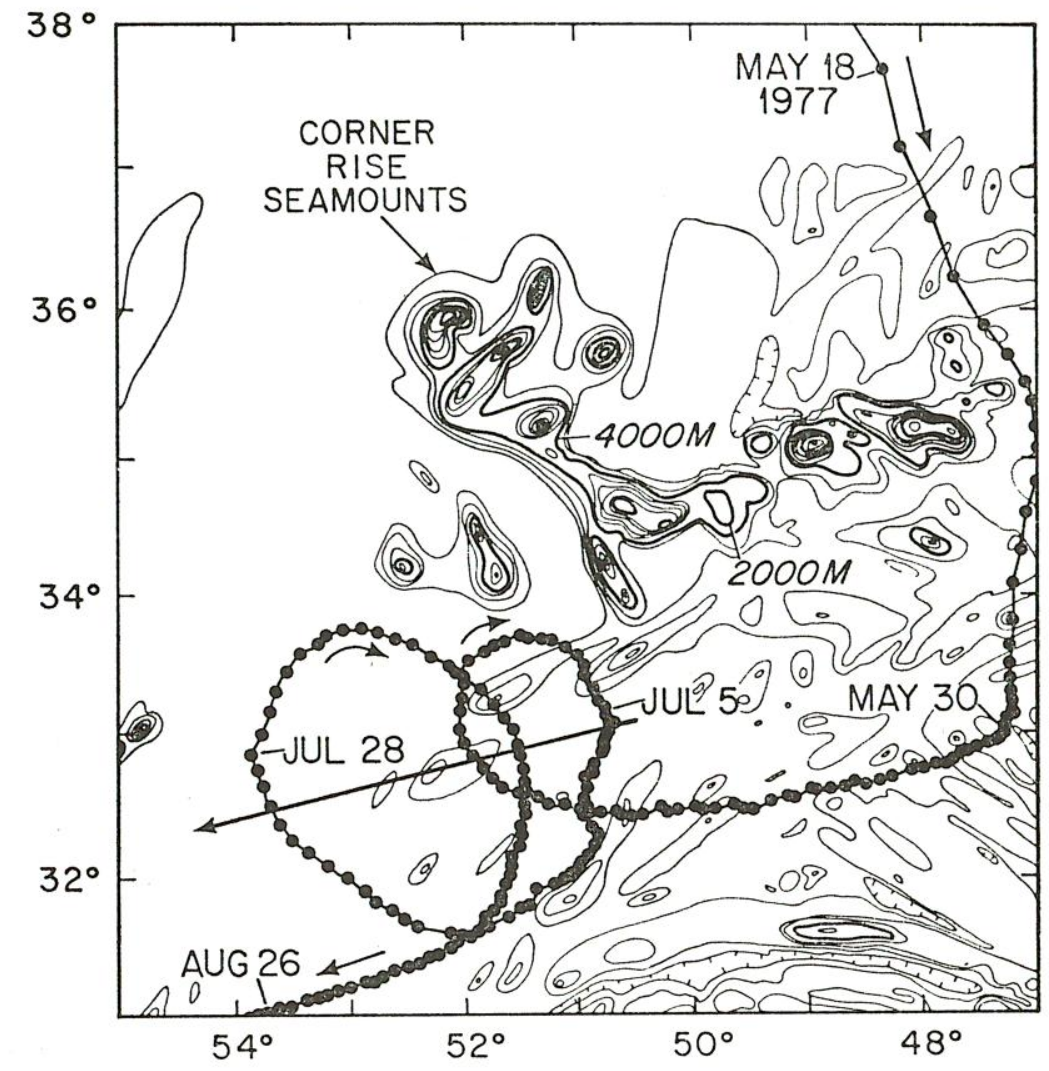

Figure 7. Trajectory of buoy $1040 \mathrm{~A}$ which looped from mid-June to mid-August, 1977 in a second, older eddy, Eddy II, which drifted southwestward with an estimated speed of 4 $\mathrm{cm} / \mathrm{sec}$.

0113B and the apparent deflection of the buoys around the seamounts have approximately the same spatial scale as the cluster of seamounts. However, small (30 km diameter), quick (3-6 day period), clockwise loops are seen in the trajectory of 1076A superimposed on the larger scale dominant loops. The small loops appear to be the same scale as individual seamounts and may have been generated by them.

\section{Temperature measurements}

During the period October 19-23, 1977 as buoys 0113B and 1076A were both looping in Eddy I, five ships conducted an XBT survey which passed through it (Dugan and Schuetz, 1978). The center position of Eddy I, determined from the 


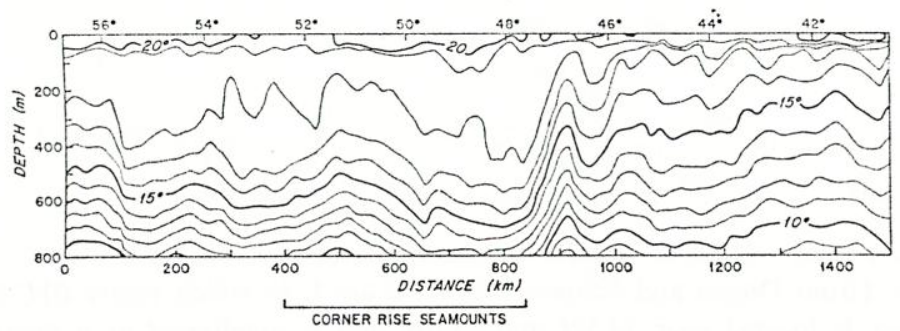

Figure 8. An east-west XBT section from KNORR 66 near 37N from May 29-June 1, 12 days after buoy 1040A moved southward across this latitude. This section and another XBT survey by Dugan, Schuetz, and Wilson (1978) from May 2-6 indicate that a significant branch of the Gulf Stream or its recirculation was flowing southward near $47 \mathrm{~W}$. Buoy $1040 \mathrm{~A}$ was embedded in this branch and was moving with a speed of $135 \mathrm{~cm} / \mathrm{sec}$ (averaged between 36 and $39 \mathrm{~N}$ ).

two buoys, matches exactly with a depression of the thermocline in which the $14^{\circ}$ isotherm extended below $750 \mathrm{~m}$ (Figs. 9-11). The thermocline depression indicates the presence of a warm core eddy which is elongated in a northwest-southeast direction and which is approximately $200 \mathrm{~km}$ in diameter. The velocity of the buoys was directed nearly parallel to the depth contours of the $14^{\circ}$ surface near the 600 and $650 \mathrm{~m}$ depths (Fig. 10). The warm eddy was embedded in a colder region where the $14^{\circ}$ isotherm was $300-500 \mathrm{~m}$ shallower than in the eddy center; the shallow regions were located to the west, south, and east of the eddy.

A possible explanation of a second depression of the thermocline near $33.0 \mathrm{~N}$ $55.5 \mathrm{~W}$ (Fig. 10) is that it is the remnant of Eddy II in which buoy 1040A was looping (Fig. 7). Buoy 1040A looped twice from mid-June to mid-August, 1977. An extrapolation of the movement of Eddy II, implied by the successive loops, forward in time to the date of the October 1977 XBT survey, suggests that Eddy II would have been near $32 \mathrm{~N} 56 \mathrm{~W}$, very close to the small depression in which the $14^{\circ}$ isotherm extended below $700 \mathrm{~m}$. Because this depression lies on the southern edge of the XBT survey it is not well resolved; the depression could extend southward and be considerably larger than shown in Fig. 10. A larger size would be more consistent with the earlier loops made by buoy 1040A. Note that both depressions, the well-documented warm eddy near $34.5 \mathrm{~N} 53.0 \mathrm{~W}$ and the second one near $33.0 \mathrm{~N} 55.5 \mathrm{~W}$, lie on a line running southwestward from the center of the Corner Rise seamount cluster near 35.8N 51.5W. If Eddy I had continued to move southwestward, it would have reached the location of the second depression by the end of December, 1977.

In summary, during the period May-September 1977, three buoys suggested that a branch of the Gulf Stream flowed southward toward the Corner Rise with speeds of 30-135 cm/sec. By early August, 1977 an anticyclonic eddy (Eddy I) formed over the seamount cluster and by October 1 the eddy began to drift south- 


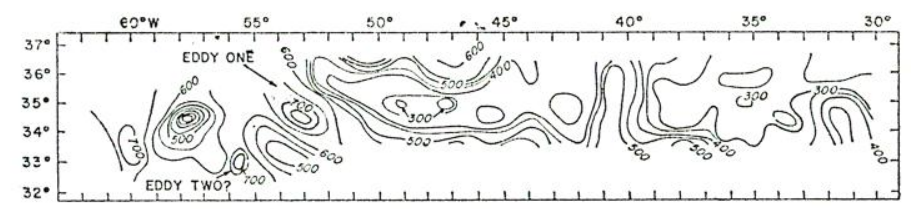

Figure 9. Chart of the depth of the $14^{\circ}$ isotherm, October 19-23, 1977 based on a five-ship XBT survey (from Dugan and Schuetz, 1978). Eddy I, in which buoys 0113B and 1076A were looping, is located near $34.5 \mathrm{~N}$ and $53.0 \mathrm{~W}$ and is manifested as a depression in the thermocline in which the $14^{\circ} \mathrm{C}$ isotherm extended below $750 \mathrm{~m}$. This warm core eddy is elongated in a northwest-southeast direction; the size of the $650 \mathrm{~m}$ contour is approximately 120 by $240 \mathrm{~km}$, but the eddy may be larger than this. The cold water or "ridge" in the thermocline extending westward to $53^{\circ}$ near $35-36 \mathrm{~N}$ overlies the Corner Rise seamounts.

westward away from the seamounts. Eddy I, which was approximately $200 \mathrm{~km}$ in diameter, moved southwestward with a mean speed of $5 \mathrm{~cm} / \mathrm{sec}$ at least until early December when the last buoy came out of it. During October an XBT survey revealed that Eddy I had a warm core, manifested as a depression of the main thermocline in which the $14^{\circ}$ isotherm extended below a depth of $750 \mathrm{~m}$. A second eddy (Eddy II), older than Eddy I, was also observed to drift southwestward from the Corner Rise during the period June 10 to August 20. An extrapolation of its course and speed suggests that Eddy II could be the second warm core eddy seen in the XBT survey.

\section{Discussion}

The implication of these results is that, periodically, warm core eddies form near the Corner Rise seamounts and that they subsequently drift southwestward. These eddies, which are manifested in the thermocline as a series of depressions separated by elevations, form a wake region downstream of the Corner Rise.

Although both the measured speeds and thermocline displacements suggest that these eddies are as large and nearly as energetic as Gulf Stream rings, it is important to note that these eddies are not rings. First, anticyclonic rings form north of the Stream, not south of it. Second, cyclonic rings which do form south of the Stream have counterclockwise circulation and cold cores, opposite to what we observed here. Third, the period of rotation in rings is usually a few days, much faster than the period of the eddies which ranged from 8-35 days.

There is the possibility that Eddy I was generated by a process unrelated to the seamounts (baroclinic instability, for example), but three aspects of the buoy trajectories suggest that the seamounts were of primary importance to this eddy's formation. First, buoy 0113B stopped directly in front of the seamounts and then made four loops directly over them. Second, all three buoys, 0113B, 1040A, $1076 \mathrm{~A}$, looped in a clockwise sense, the same as that predicted in models of eddies 


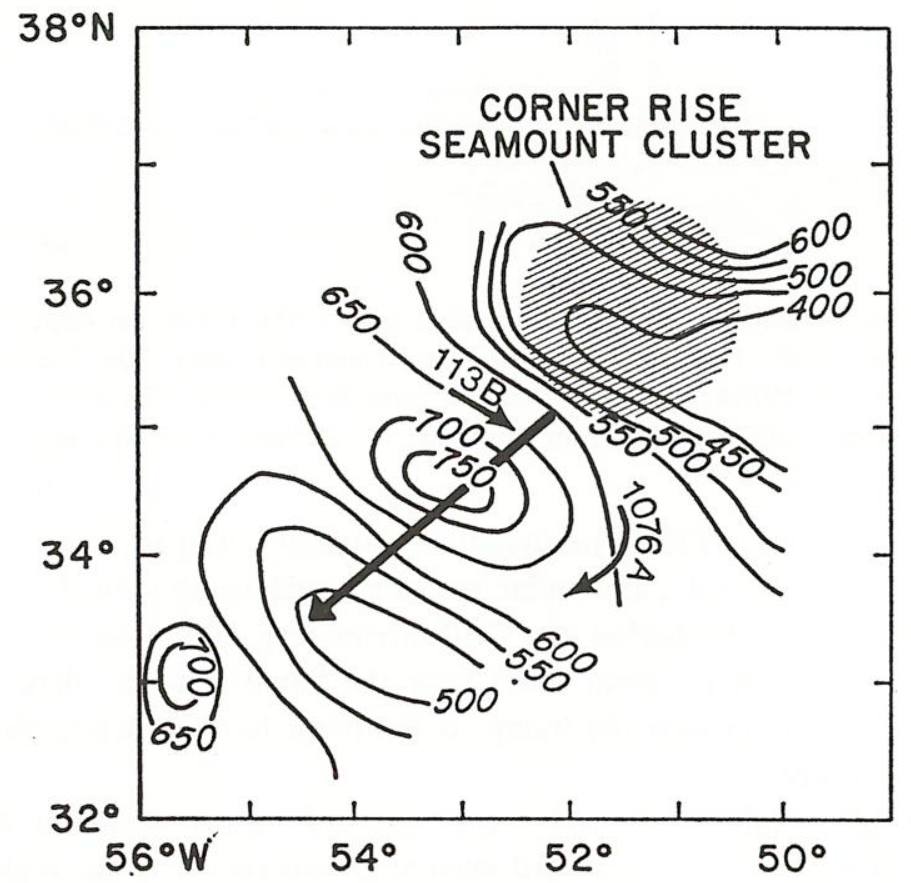

Figure 10. Large scale chart of the depth of the $14^{\circ}$ isotherm near the Corner Rise seamounts. The movement of the buoys at the time of the XBT survey and overall movement of Eddy I are shown with arrows.

(Taylor columns) trapped over topographic bumps. Third, all three buoys appeared to be deflected to the left as they approached the seamounts. Models of westward flow impinging on an isolated bump also show a leftward deflection (looking downstream) of streamlines around the bump; the deflection is accompanied by a crowding of streamlines on the left of the bump (Hogg, 1973; McCartney, 1975).

The warm core of Eddy $\mathrm{I}$ is also in agreement with some model topographic eddies. Taylor columns in stratified flow can have either a warm or cold core depending on the flow characteristics, specifically the amount of vertical shear in the horizontal currents and amount of flow around the bump. For no shear, a cold core anticyclonic eddy forms over a topographic bump as surrounding water is advected onto it and vortex lines are compressed (Huppert and Bryan, 1976). The inclusion of vertical shear gives rise to a horizontal temperature (and density) gradient due to the thermal wind relation. For this case, which is more appropriate to the Gulf Stream system, a warm core anticyclonic eddy can form over a bump caused by the lateral deflection of the streamlines over the bump (Hogg, 1973; McCartney, 1975, 1976). The origin of a warm core topographic eddy can be understood by envisioning a start-up process in which topography is "created" at 


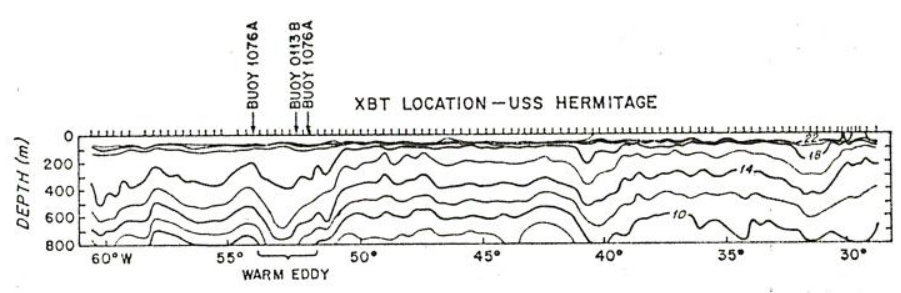

Figure 11. Vertical temperature section measured with XBTs across the center of the warm eddy, October 19-23, 1977 (J. Dugan, personal communication). The locations at which buoys $0113 \mathrm{~B}$ and 1076A crossed the section have been added. The eddy is seen by the depression in the main thermocline, in which the $14^{\circ}$ isotherm reached a depth of $753 \mathrm{~m}$.

time zero (McCartney, 1976). The streamlines, initially straight, feel the topography and deflect with time until a streamline meanders sufficiently strongly to close back on itself much like the formation of a Gulf Stream ring. The eddy has a warm core if the lateral advection of warm water over the bump is larger than the vertical advection of cold water over the bump. If the latter term is larger, then the eddy can have a cold core.

Models predict different behavior for eastward versus westward flow past a bump; the perturbation in a westward current is constrained to the region near the bump whereas an eastward current has a complicated Rossby wake downstream of the bump (McCartney, 1975). Under certain conditions the wake has a train of embedded eddies, both cold core cyclonic and warm core anticyclonic. In both westward and eastward flow the eddy trapped over the bump can have a warm core. Based on the southwestward movement of the eddies and the results of other studies, the flow past the Corner Rise appears to be "westward". One should be cautioned that $\mathrm{f} / \mathrm{h}$ contours near the Corner Rise (Rhines, 1969) are complicated and that one could conclude that the flow was "eastward" if north is defined to lie in the direction of increasing $\mathrm{f} / \mathrm{h}$ values.

There remains to be explained how the observed eddy left the seamounts. It seems evident from Taylor column theory that a time change in flow can result in a change of the characteristics of the trapped eddy as well as a shed eddy (to balance vorticity). An unsteady model that has flow increasing from rest but that does not include vertical shear (Huppert and Bryan, 1976) predicts that water shed from a bump sinks and produces a warm core cyclonic eddy. The shed eddy can become trapped near the bump or can be advected downstream depending on the specific flow regime. Although the shed model eddy has opposite rotation to that of Eddy I, the model does give an example of how eddies can be shed from topography by time varying flow. One can also imagine that once formed a topographic eddy might be swept away by either a sudden increase in the velocity of the surrounding fluid or by means of an instability process, perhaps similar to that which occurs 
in a Kármán vortex street. A more detailed comparison with theory is problematic at this time because the Corner Rise seamounts are considerably higher and in a more complex configuration than the usual small isolated bump assumed in models; at the same time the Gulf Stream recirculation is more jet-like and variable than the broad, straight impinging model flow. It will be interesting to see if topographically generated eddies will appear in some of the finer grid numerical models of the general circulation when realistic seamounts are included.

The temperature, circulation, and trajectory of Eddy I resemble the characteristics of the Aries eddy, a thick lens of $18^{\circ} \mathrm{C}$ water, $200 \mathrm{~km}$ in diameter, rotating clockwise with speeds of $50 \mathrm{~cm} / \mathrm{sec}$ (J. Swallow, 1971). The Aries eddy was observed in October and November, 1959 as it moved toward a direction of $252^{\circ} \mathrm{T}$ with a steady speed of $5 \mathrm{~cm} / \mathrm{sec}$. When its course and speed are extrapolated backward in time 2.5 months, the trajectory intersects Bermuda (M. Swallow, 1961) hinting that this eddy may also have been topographically generated. If one continues the extrapolation even farther, the trajectory intersects the southern end of the New England seamount chain and the Corner Rise seamount cluster, two likely source regions of topographic eddies.

Acknowledgments. This is contribution number 4450 from the Woods Hole Oceanographic Institution and 136 from the Mid-Ocean Dynamics Experiment (POLYMODE). The research was funded by the National Science Foundation (Grant OCE78-18017), the Office of Naval Research (Contract N00014-74-C-0262, NR 083-004) and the United States-France Exchange of Scientists program, which is sponsored by the National Science Foundation and the Centre National de la Recherche Scientifique. The buoys were launched on two cruises; KNORR 65 and 66. I thank Valentine Worthington, Gordon Volkmann, George Knapp, and the WHOI Buoy Group for their efforts during the second of these cruises and for permission to use their XBT data. John Dugan and Armin Schuetz generously provided their unpublished XBT survey data. NASA calculated and provided buoy position data. Nelson Hogg, Michael McCartney and Brechner Owens gave helpful comments concerning Taylor columns. This manuscript was written during a visit to the Muséum d'Histoire Naturelle in Paris.

\section{REFERENCES}

Dugan, J., A. Schuetz, and S. Wilson. 1978. Thermocline structure south of the Newfoundland Rise: An XBT swath. POLYMODE News 30 (Unpublished manuscript).

Dugan, J. and A. Schuetz. 1978. Multi-ship XBT survey across the Ridge at 35N. POLYMODE News 48 (Unpublished manuscript).

Hogg, N. G. 1973. On the stratified Taylor column. J. Fluid Mech., 58, 517-537.

Huppert, H. E. and K. Bryan. 1976. Topographically generated eddies. Deep-Sea Res., 23, 655-679.

McCartney, M. S. 1975. Inertial Taylor columns on a beta plane. J. Fluid Mech., 68(1), 71-95.

- 1976. The interaction of zonal currents with topography with applications to the Southern Ocean. Deep-Sea Res., 23, 413-427.

McGregor, B. A., P. R. Betzer, and D. C. Krause. 1973. Sediments in the Atlantic Corner Seamounts: Control by topography, paleo-winds, and geochemically-detected modern bottom currents. Marine Geology, 14, 179-190. 
Naval Oceanographic Office. 1978. Surface Currents, West Central North Atlantic Ocean, N00 SP1400-NA6. Naval Oceanographic Office, NSTL Station, Bay St. Louis, MS 39522.

Rhines, P. B. 1969. Slow oscillations in an ocean of varying depth. Part 1. Abrupt topography. J. Fluid Mech., 37, 161-189.

Richardson, P. L., J. J. Wheat, and D. Bennett. 1979. Free-drifting buoy trajectories in the Gulf Stream system (1975-1978). A data report. Woods Hole Oceanographic Institution Technical Report, WHOI-79-4.

Schmitz, W. J., Jr. 1979. Weakly depth-dependent segments of the North Atlantic circulation. J. Mar. Res., 38, 111-133.

Stommel, H., P. Niiler, and D. Anati. 1978. Dynamic topography and recirculation of the North Atlantic. J. Mar. Res., 36, 449-468.

Swallow, J. C. 1971. The Aries current measurements in the western North Atlantic. Phil. Trans. Roy. Soc. London, A270, 451-460.

Swallow, M. 1961. Deep currents in the open ocean. Oceanus, 7, 2-8.

Uchupi, E. 1971. Bathymetric atlas of the Atlantic, Caribbean, and Gulf of Mexico. Woods Hole Oceanographic Institution Technical Report WHOI 71-71.

Worthington, L. V. 1976. On the North Atlantic circulation. Johns Hopkins Oceanographic Ser., Vol. 6, 110 pp. Johns Hopkins University Press, Baltimore, MD.

Received: 11 November, 1979; revised: 14 July, 1980.

Printed in U.S.A. for the Sears Foundation for Marine Research, Yale University, New Haven, Connecticut, 06520, U.S.A.

Van Dyck Printing Company, North Haven, Connecticut, 06473, U.S.A. 
MANDATORY DISTRIBUTION LIST

FOR UNCLASSIFIED TECHNICAL REPORTS, REPRINTS, AND FINAL REPORTS

PUBLISHED BY OCEANOGRAPHIC CONTRACTORS

OF THE OCEAN SCIENCE AND TECHNOLOGY DIVISION

OF THE OFFICE OF NAVAL RESEARCH

(REVISED NOVEMBER 1978)

1 Deputy Under Secretary of Defense

(Research and Advanced Technology)

Military Assistant for Environmental Science

Room 3D129

Washington, D.C. 20301

Office of Naval Research

800 North Quincy Street

Arlington, VA 22217

3 ATTN: Code 483

1 ATTN: Code 460

2 ATTN: 102B

1 CDR J. C. Harlett, (USN)

ONR Representative Woods Hole Oceanographic Inst.

Woods Hole, MA 02543

Commanding Officer

Naval Research Laboratory

Washington, D.C. 20375

6 ATTN: Library, Code 2627
12 Defense Documentation Center Cameron Station

Alexandria, VA 22314

ATTN: DCA

Commander

Naval Oceanographic Office

NSTL Station

Bay St. Louis, MS 39522

1 ATTN: Code 8100

1 ATTN: Code 6000

1 ATTN: Code 3300

1 NODC/NOAA

Code D781

Wisconsin Avenue, N.W.

Washington, D.C. 20235 


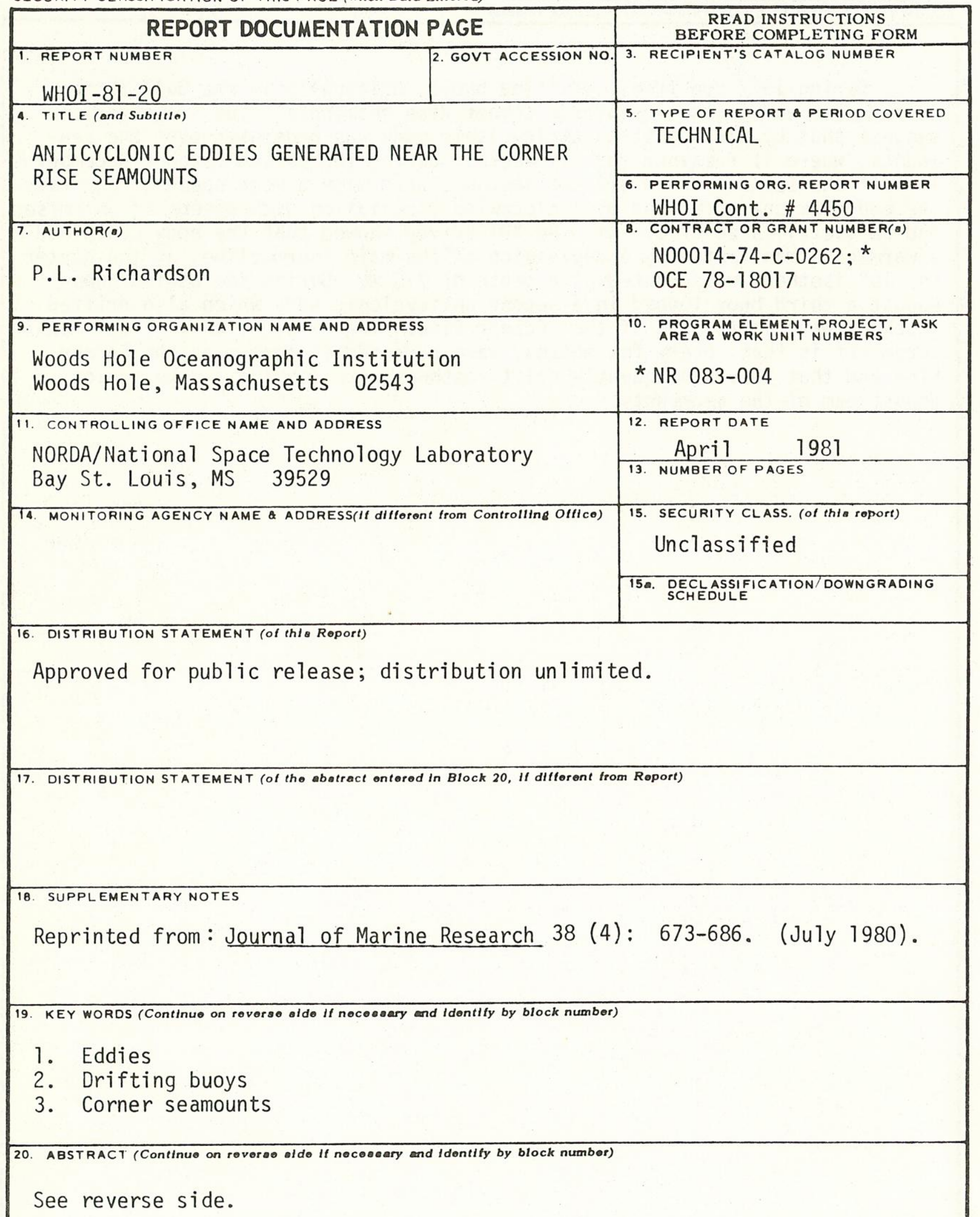


During 1977 two freely drifting buoys, originally in the Gulf Stream, looped over and in the lee of the Corner Rise seamounts. The trajectories suggest that by mid-August an anticyclonic eddy was generated over the seamounts, where it remained for six weeks. During the period October-December it left the seamounts and drifted southwestward with a mean speed of $5 \mathrm{~cm} / \mathrm{sec}$. The eddy was characterized by a clockwise circulation with speeds of $30 \mathrm{~cm} / \mathrm{sec}$ and an overall size of $200 \mathrm{~km}$. An XBT survey showed that the eddy contained a warm core manifested by a depression of the main thermocline, at the center the $15^{\circ}$ isotherm was located at a depth of $715 \mathrm{~m}$. During the period JuneAugust a third buoy looped in a second anticyclonic eddy which also drifted southwestward in the lee of the Corner Rise. The implication of these measurements is that, every few months, warm core eddies form near the Corner Rise and that they subsequently drift southwestward forming a wake region downstream of the seamounts. 


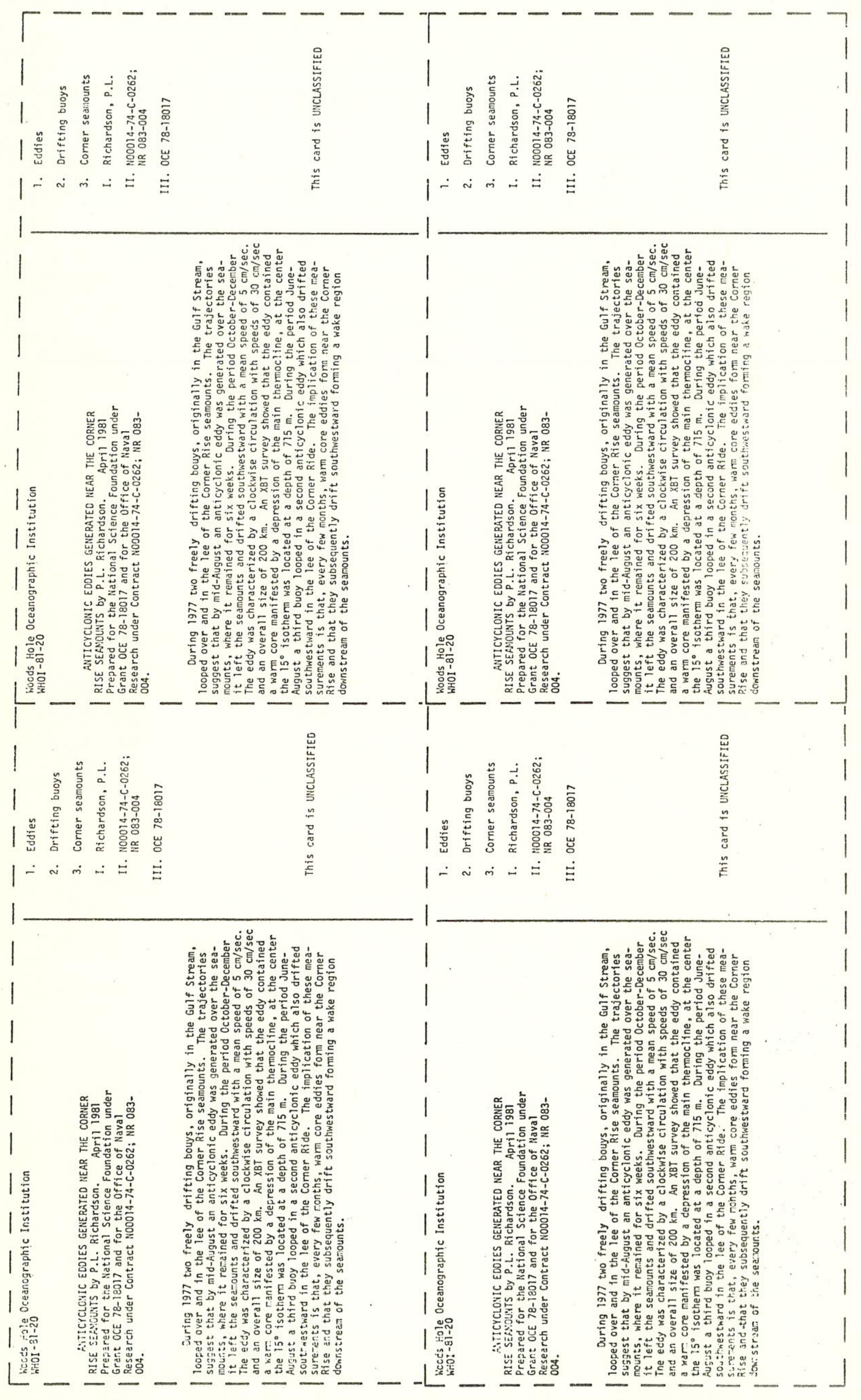

